\title{
ERRATUM
}

\section{Erratum to: Protozoa and human macrophages infection by Legionella pneumophila environmental strains belonging to different serogroups}

Patrizia Messi - Annalisa Bargellini • Immacolata Anacarso - Isabella Marchesi • Simona de Niederhäusern · Moreno Bondi

Published online: 15 December 2012

(c) Springer-Verlag Berlin Heidelberg 2012

\section{Erratum to: Arch Microbiol}

DOI 10.1007/s00203-012-0851-9

Unfortunately, the given and family names of the authors (except the fifth author) have been inadvertently interchanged in the original version. The correct names in the author group should read as given below:

Patrizia Messi - Annalisa Bargellini - Immacolata Anacarso $\bullet$ Isabella Marchesi $\bullet$ Simona de Niederhäusern • Moreno Bondi

The online version of the original article can be found under doi:10.1007/s00203-012-0851-9.

P. Messi $(\bowtie)$ - I. Anacarso · S. de Niederhäusern · M. Bondi Department of Life Sciences, University of Modena and Reggio Emilia, Via Campi 287, 41125 Modena, Italy

e-mail: patrizia.messi@unimore.it

\section{A. Bargellini · I. Marchesi}

Department of Diagnostic Medicine, Clinical and Public Health, University of Modena and Reggio Emilia, Via Campi 287, 41124

Modena, Italy 